\title{
Effect of particle size on the viscosity of nanofluids: A review
}

Halil Dogacan Kocaa, Serkan Doganay ${ }^{\mathrm{b}}$, Alpaslan Turgut ${ }^{\mathrm{c}}$, Ismail Hakki Tavman ${ }^{\mathrm{c}}$, R. Saidur $\mathrm{d}, \mathrm{e}$, Islam Mohammed Mahbubul ${ }^{\mathrm{f}}$

aDokuz Eylul University, The Graduate School of Natural and Applied Sciences, Mechanical Engineering Department, Tinaztepe Campus, Buca 35397, Izmir-Turkey

bDokuz Eylul University, The Graduate School of Natural and Applied Sciences, Mechatronics Engineering Department, Tinaztepe Campus, Buca 35397, Izmir-Turkey

'Dokuz Eylul University, Engineering Faculty, Mechanical Engineering Department, Tinaztepe Campus, Buca 35397, Izmir-Turkey

dResearch Centre for Nanomaterials and Energy Technology (NMET), School of Science and Technology, Sunway University, No. 5, Jalan Universiti, Bandar Sunway, Petaling Jaya, 47500 Selangor Darul Ehsan, Malaysia

eDepartment of Engineering, Lancaster University, Lancaster, LA1 4YW, UK

${ }^{f}$ Center of Research Excellence in Renewable Energy (CoRERE), Research Institute, King Fahd University of Petroleum \& Minerals (KFUPM), Dhahran 31261, Saudi Arabia

\section{Abstract}

Nanofluids are potential new generation heat transfer fluids, which have been investigated meticulously, in recent years. Thermophysical properties of these fluids have significant influence on their heat transfer characteristics. Viscosity is one of the most important thermophysical properties that depends on various parameters. Size of the particles used in nanofluids is one of these effecting parameters. In this work, experimental studies considering the particle size effect on the viscosity of the nanofluid have been reviewed. Firstly, comparison of nanofluid and surfactant type, production and measurement methods were considered. Viscosity results of selected studies were evaluated in view of the parameters such as particle size, temperature and concentration. Furthermore, effective viscosity models of nanofluids, which include particle size as a parameter were discussed. The results indicate that there is a discrepancy about the effect of particle size on the viscosity of nanofluids. Moreover, it is observed from the evaluated data that the relative viscosity variation can be almost $40 \%$ either upwards or downwards by only altering the particle size. 
Keywords: Nanofluid; Nanoparticles; Size effect; Viscosity; Surfactant; Temperature.

* Corresponding author: Alpaslan Turgut

E-mail addresses: alpaslan.turgut@deu.edu.tr

\section{Nomenclature}

T

temperature $\left({ }^{\circ} \mathrm{C}\right)$

d

diameter ( $\mathrm{m})$

$\mathrm{H} \quad$ inter particle space $(\mathrm{m})$

C correction factor

V velocity $(\mathrm{m} / \mathrm{s})$

m constant of system properties

h hydrodynamic

$r \quad$ thickness of the capping layer $(m)$

$\mathrm{N} \quad$ Avogadro's number $\left(6.022 \times 10^{23} \mathrm{~mol}^{-1}\right)$

M molecular weight $(\mathrm{kg} / \mathrm{mol})$

\section{Subscripts}

$\mathrm{nf}$

nanofluid

bf base fluid

p particle

o reference

f fluid

\section{Abbreviations}

SDBS sodium dodecylbenzenesulfonate

PG propylene glycol

EG ethylene glycol 
vol. $\quad$ volumetric

wh. weight

A.T. ambient temperature

\section{Greek letters}

$\begin{array}{ll}\mu & \text { viscosity (Pa.s) } \\ \varphi & \text { volume concentration (\%) } \\ \rho & \text { density }\left(\mathrm{kg} / \mathrm{m}^{3}\right) \\ \delta & \text { distance between the centers of particles }(\mathrm{m}) \\ \alpha, \omega, \mathrm{V} & \text { empirical constants } \\ \lambda, \sigma & \text { exponents }\end{array}$

\section{Introduction}

Technology driven world enforces the researchers to explore more and more in thermal engineering. Currently, one of the most crucial pursuits of thermal engineers is to provide efforts on new types of heat transfer fluids. Thermal engineers found that the addition of solid particles to a base fluid can provide the fluid a better heat transfer capability. Based on this concept, a new generation fluid named as "nanofluid" has occurred in the field for the last two decades. Typically, water, ethylene glycol, oil, etc. are employed as base fluids, which have naturally poor thermal conductivities. Supplementation of nano-scaled metals, metal oxides or carbon based materials to these base fluids brings out the nanofluids. Although the idea was first conceived by Masuda et al. [1], Choi [2] was the one who had named it as nanofluid. Just after their inventions, a number of nanofluid related papers have increased expeditiously [3] as can be seen in Fig. 1. 
Fig. 1. Number of publications containing the term nanofluid in literature.

Recent literature reveals that nanofluid based systems have an extensive potential area such as, solar collectors [3,4], electronics cooling [6-8], automotive [9,10], nuclear reactor cooling [11], refrigerators [12-14], heat exchangers [15,16]. The potential utilization of such a colloidal mixture for many divergent systems exposed the requisiteness of meticulous investigation on thermal properties of the nanofluids. One of the pioneering studies on the thermal conductivity by Lee et al. [17] concluded that the presence of nanoparticles provides substantially higher thermal conductivity than the same liquid without particle addition. Eastman et al. [18] prepared a nanofluid by adding copper nanoparticles into the ethylene glycol and they observed a thermal conductivity increment up to $40 \%$. Xie et al. [19] studied the thermal conductivity of $\mathrm{Al}_{2} \mathrm{O}_{3}-$ ethylene glycol nanofluid. The conclusion, which is in accordance with the former one, included that the thermal conductivity of the suspension was much higher than the base fluid. Although the goal of adding nano sized particles to a base fluid is to achieve higher thermal conductivity values, the thermal conductivity is not the sole property that influences the heat transfer. It is also viscosity that is playing a key role on characterizing the heat transfer behavior of a nanofluid [20]. Li et al. [21] was one of the first groups who investigated the transport properties of nanofluids and observed that the viscosity was not only affected by the volume concentration, but also the size of nanoparticles.

Ascending of nanofluid researches on convective heat transfer brought out many viscosity based studies. Pozhar [22] made theoretical and simulation efforts to predict the nanofluids' viscosity at the very beginning. Then, Wang et al. [23] proposed a modified viscosity equation from Einstein's classical viscosity model for suspensions by considering spatial distribution of nanoparticle clusters and adsorption liquid 
molecules on nanofluid surfaces. Many experimental studies followed them and it is exposed that viscosity of nanofluids is fairly dependent on several parameters such as temperature, volume concentration, aggregation, particle shape, surfactant, particle size, etc. [24,25]. It is also influenced by the ultrasonication period used during nanofluid preparation [26]. Turgut et al. [27] made an experimental effort on measuring the viscosity of $\mathrm{TiO}_{2}-$ water nanofluid. They observed a decrement in viscosity values by increasing temperature. Sundar et al. [28] prepared a review paper on viscosity, which affirms the results of Turgut et al. [27] in terms of temperature. Bahiraei et al. [29] and Sundar et al. [28] conducted experiments to interpret the effect of vol. concentration on viscosity by using $\mathrm{Fe}_{3} \mathrm{O}_{4}-$ water $(0.1-1 \%)$ and $\mathrm{TiO}_{2}-$ water $(0-2 \%)$ nanofluids, respectively. They both concluded that the viscosity was increased by the increase of vol. concentration. Aggregation also plays an important role on the viscosity of nanofluids [30]. Gaganpreet et al. [31] focused on fractal aggregates and interfacial layer around the nanoparticle to determine the rheological behavior of nanofluids. It was found that the increase in effective radius of the aggregates lead to a substantial viscosity increment. In addition to the aggregation, viscosity of nanofluids depends on the particle shape [32]. Timofeeva et al. [32] recommended the use of nanoparticles with spherical shape for lower viscosity values. In accordance with the recommendation of Timofeeva et al. [32], the study of Jeong et al. [33] concluded that the viscosity for the nanofluid with nearly rectangular shape particles were $7.7 \%$ higher than that of the one with spherical shape. Stability is an essential point to be ensured for a colloidal mixture. Use of a surfactant can be an effective way to achieve a stable behavior for nanofluids [34]. Li et al. [35] used sodium dodecylbenzenesulfo nate (SDBS) as a surfactant for $\mathrm{Cu}$-water suspension. They found out that viscosity of the $\mathrm{Cu}$-water nanofluid increased slightly by increasing the mass concentration of SDBS 
dispersant. Moreover, a more recent study [36] has employed two types of surfactants to improve the stability of $\mathrm{TiO}_{2}$, polycarboxylate and trioxadecane acid. They found out that $\mathrm{TiO}_{2}$ with polycarboxylate surfactant has a higher viscosity than the one with trioxadecane acid. Thus they concluded that the increment of viscosity may be dependent on the surfactant type. The influence of the size of dispersed nanoparticles on viscosity is another critical parameter. Many review studies related with particle size are available in the literature. Sergis et al. [37] reviewed the anomalous heat transfer modes of nanofluids. They mentioned that the trend seemed to be as effective viscosity increasing while particle size decreasing. Kumar et al. [38] and Mishra et al. [39] reported that there is no report on critical particle size to achieve stability and less agglomeration. Elcioglu et al. [40] emphasized the particle agglomeration possibility. According to their findings, particle agglomeration should be considered while evaluating the particle size effect. Nwosu et al [41] reviewed the viscosity models available in literature and they concluded that particle and aggregation sizes should be taken into account while proposing new viscosity models in further studies. Sharma et al. [42] suggested that, particle size and particle shape optimization can be carried out for each type of nanofluid which may be helpful in synthesizing a new class of nanofluids with better rheological properties. Bashirnezhad et al. [43] concluded that considering the effect of particle size, aggregation, sonication time, $\mathrm{pH}$ at the same time with particle concentration leads to generate more accurate viscosity correlations. In a more recent study, Zhao et al. [44] presented and discussed the data driven modeling of thermalphysical properties of nanofluids for automotive radiator by considering the particle size. According to observations of Akilu et al. [45] it is apparent that contradictions exist in particle size effect studies. They mentioned that such discrepancies can mostly be caused from experimental procedures and instrument 
calibration. Another review on nanofluid viscosity by Sundar et al. [28], reported a contradiction that three types of conclusions are available in literature in terms of the size effect; increase in relative viscosity by decreasing particle size or by increasing particle size and no significant effect of particle size.

In perusing the nanofluid related literature, there are still discrepancies between papers about the particle size effect on viscosity. This study aims to review and discuss the systematic experimental studies which have investigated the particle size effect on nanofluid viscosity. In other words, data from studies which have made viscosity measurements with same nanofluid sample for different particle sizes are collected, analyzed and discussed. Although, there are several reviews [25,28,30,38-47] which include the particle size effect as part of an overall nanofluid viscosity review, no review available completely focused on the effect of particle size on the viscosity of nanofluids. Some of these reviews only referred to the results of studies, cited in text, and some of them $[30,38-40,46,47]$ recommended the development of more accurate correlations $[25,28]$ or more quality work [42] in order to be able to comment the particle size effect on the viscosity. Another goal of this work is to discuss the reasons far beyond discrepancies between particle size effect related studies. Authors hope that it is the first time that the particle size effect on nanofluid viscosity is discussed based on samples utilized in the same studies unlike the other existing reviews. Moreover, it is the first time that the parameters which need to be considered are discussed for the investigation of the particle size effect.

\section{Experimental studies about the effect of particle size on the viscosity}

Many experimental and numerical investigations on the relative viscosity of nanofluids have been conducted. Table 1 indicates the available experimental studies 
$[36,48-67]$ on the relative viscosity of nanofluids by considering the particle size effect. The table includes specifications of these studies such as; base fluid, nanoparticle type, particle size, particle shape, particle vol. concentration and temperature. It is clearly seen that the most popular base fluid is water and the most commonly used nanoparticle is $\mathrm{Al}_{2} \mathrm{O}_{3}$. The reason is probably due to the low cost and the high thermal conductivity of $\mathrm{Al}_{2} \mathrm{O}_{3}$ nanoparticles compared to the other nanoparticles [68].

To perform a more detailed analysis for the available literature, Table 2 is provided. The table involves information of the surfactant type, production and measurement method and the suppliers of experimented samples. Generally, rotational type of viscometer has been used to measure the viscosity of nanofluids and all samples given in the table were produced by the two step method. Additionally, most of the cases involve an ultrasonication process to obtain uniform and stable suspensions.

Table 1 Summary of process parameters of some experimental investigations on viscosity.

Table 2 Summary of the background information of some experimental investigations on viscosity.

Fig. 2. Selected experimental data for the relationship between relative viscosity and particle size.

The relative viscosity of nanofluids as a function of the particle size is shown in Fig. 2. Viscosity values of nanofluids are normalized by the values of base fluids to provide a better comparison. Evaluation of the considered papers in this review exposed that some of them $[36,48-50]$ indicated an increment in the relative viscosity of nanofluids with increasing particle size. He et al. [48] carried out viscosity 
measurements on $\mathrm{TiO}_{2}-$ water nanofluid with different concentrations $(0.25,0.6$ and 1.2 vol.\%) and different particle sizes $\left(95,145\right.$ and $210 \mathrm{~nm}$ ) at $22^{\circ} \mathrm{C}$. Bohlin CVO rheometer with a Mooney cell was used for the viscosity measurements. Ultrasonication was applied for 30 minutes to disperse the particles in water to break down the large agglomerates. They concluded that the relative viscosity of nanofluids increases with increasing particle size and particle concentration. Furthermore, the non-linearity of the dependence of the nanofluid relative viscosity on particle concentration is more considerable than the particle size. Nguyen et al. [49] measured the viscosity of $\mathrm{Al}_{2} \mathrm{O}_{3}-$ water nanofluid in the temperature range of $20-50^{\circ} \mathrm{C}$. Particle vol. concentrations of the nanofluid ranging from 1 to $9 \%$ were tested. They applied an ultrasonication for 30 minutes to mix the nanofluid. Although utilization of a surfactant for the preparation of nanofluids was mentioned, the type of the surfactant was not specified. Viscosity measurement of $\mathrm{Al}_{2} \mathrm{O}_{3}$-water nanofluid was done by using a piston-type viscometer with two different sizes ( 36 and $47 \mathrm{~nm}$ ). The results show that the viscosity of the sample with $47 \mathrm{~nm}$ particle size is clearly higher than the sample with $36 \mathrm{~nm}$ particle size. The relative viscosity values of these samples seem to be higher when compared to the results of other papers. Moreover, they developed viscosity correlations for water based $\mathrm{Al}_{2} \mathrm{O}_{3}$ nanofluid for both particle sizes:

$$
\begin{aligned}
& \frac{\mu_{n f}}{\mu_{b f}}=0.904 e^{0.148 \varphi}(47 n m) \\
& \frac{\mu_{n f}}{\mu_{b f}}=1+0.025 \varphi+0.015 \varphi^{2}(36 n m)
\end{aligned}
$$

Jarahnejad et al. [36] used two viscometers (a capillary and a falling ball) for the measurements of $\mathrm{Al}_{2} \mathrm{O}_{3}-$ water and $\mathrm{TiO}_{2}$-water nanofluids in the temperature range of 
$20-50^{\circ} \mathrm{C}$ and the particle concentration of $3-14.3 \mathrm{wt} . \%$. They dispersed the nanoparticles in water by high-energy tip sonication. Different surfactants purchased from different companies (octylsilane for $\mathrm{Al}_{2} \mathrm{O}_{3}$, trioxadecane acid for $\mathrm{TiO}_{2}$ and polycarboxylate for $\mathrm{TiO}_{2}$ ) were added to the base fluid in order to improve shelf-stability of nanofluids. $\mathrm{Al}_{2} \mathrm{O}_{3}$ based nanofluids have three different sizes of 200,250 and 300 $\mathrm{nm}$. However, the details of the additives for $\mathrm{Al}_{2} \mathrm{O}_{3}$ nanofluid was not revealed by the supplier due to their intellectual property rights. The results showed that the increase in viscosity of the sample with $200 \mathrm{~nm}$ is lower than the samples with 250 and $300 \mathrm{~nm}$ particle sizes at 2.4 vol.\% concentration, but a general trend cannot be inferred from the results. Furthermore, they made a comparison between both with and without surfactant and the result indicated that the surfactant most likely increases the viscosity. Also they reported that the increment in viscosity of nanofluids might be dependent on the surfactant type; for instance, $\mathrm{TiO}_{2}$ nanofluids with polycarboxylate surfactant have higher viscosity than the $\mathrm{TiO}_{2}$ nanofluids with trioxadecane acid. But, the compared nanofluids with different particle sizes (respectively 140 and $200 \mathrm{~nm}$ ) and surfactants, and the concentration of surfactant is unknown. Therefore, it is not clear that the viscosity increment of nanofluids is completely dependent on the type of surfactant. Turgut et al. [50] studied the particle size effect on the viscosity of $\mathrm{Al}_{2} \mathrm{O}_{3}-$ water nanofluid for two different sizes as 10 and $30 \mathrm{~nm}$. About 6.33 vol.\% concentrated $\mathrm{Al}_{2} \mathrm{O}_{3}-$ water nanofluids were diluted to three different concentrations, respectively 1,2 and $3 \%$. The diluted nanofluids were sonicated by the probe type ultrasound for $2 \mathrm{~min}$ at $70 \mathrm{~W}$ power. The concentration of acetic acid as a surfactant with $0.1-0.3 \%$ by wt. was used in all samples. Viscosity measurements are done by a Brookfield DV3T Rheometer in the temperature range of $5-50^{\circ} \mathrm{C}$. At all temperatures, there is a linear relationship between the shear stress and the shear rate for all samples, which 
indicates Newtonian fluid behavior. Moreover, their results depicted that the relative viscosity of $\mathrm{Al}_{2} \mathrm{O}_{3}$-water nanofluid increases with the increase of the particle size. Furthermore, the viscosity of $\mathrm{Al}_{2} \mathrm{O}_{3}$ nanofluids with 10 and $30 \mathrm{~nm}$ were 1.6 and 1.8 times greater than the viscosity of water, respectively.

From another aspect, results of some studies [51-62] indicated an increment with decrease in particle size. Namburu et al. [51] studied $\mathrm{SiO}_{2}-\mathrm{EG} /$ water $(60 \% \mathrm{EG}$, $40 \%$ water by wt.) nanofluid with various diameters of 20,50 and $100 \mathrm{~nm}$. They measured the viscosity of nanofluids between -35 and $50^{\circ} \mathrm{C}$ by a LV DV- $-1+$ Brookfield Programmable Viscometer. They claimed that the nanoparticles were well dispersed and did not aggregate more than a year when they conducted the experiments. In terms of particle size effect evaluation, they only employed 8 vol.\% concentrated $\mathrm{SiO}_{2}-$ $\mathrm{EG} /$ water nanofluid and observed an increment in the relative viscosity values as particle size decreases. In a further study, Namburu et al. [52] confirmed this behavior by using the same nanofluid sample at 6 vol.\% concentration. Moreover, they presented a viscosity correlation for $\mathrm{SiO}_{2}-\mathrm{EG} /$ water nanofluid as a function of temperature, which is valid for $50 \mathrm{~nm}$ particle size at $2-10$ vol. $\%$ concentration range.

$$
\begin{aligned}
& \log \left(\mu_{n f}\right)=A e^{-B T} \\
& A=0.1193(\varphi)^{3}-1.9289(\varphi)^{2}-2.245(\varphi)+167.17 \\
& B=-7 \times 10^{-6} \varphi^{2}-0.0004(\varphi)+0.0192
\end{aligned}
$$

Chevalier et al. [53] studied the viscosity of $\mathrm{SiO}_{2}$-ethanol nanofluid at vol. concentrations from 1.1 to $7 \%$ with three different particle sizes $(35,94$ and $190 \mathrm{~nm})$. The preparation of the samples was made by stiring them for 2 hours. They used a capillary viscometer at ambient temperature for the measurements of the viscosity of 
the nanofluids. Their results showed that the relative viscosity of nanofluids is largely dependent on the particle size and increases when the particle size is smaller. Also, they compared their results with Krieger-Dougherty equation [69] and reported a good agreement. Lu et al. [54] and Kwek et al. [55] investigated the effect of the particle size on $\mathrm{Al}_{2} \mathrm{O}_{3}-$ water nanofluid at 5 vol.\% concentration. Lu et al. [54] evaluated the viscosity of nanofluid both numerically and experimentally. Water and EG were employed as the base fluids for preparing the nanofluid samples. To avoid the agglomeration, sonication process was applied. They obtained a good agreement between the numerical results of simplified molecular dynamics (MD) simulation and the experimental data. They reported that the relative viscosity of nanofluids increases with the decrease in the particle size. However, the tendency is almost invariable when the diameter of nanoparticle is greater than $30 \mathrm{~nm}$. Since some viscosity data are lower than that of the base fluid, they have not been shown in Fig. 2 for clarification of the illustration. Kwek et al. [55] added CTAB as a surfactant to the $\mathrm{Al}_{2} \mathrm{O}_{3}-$ water nanofluids to keep the particles well-dispersed in the base fluid. Then, the nanofluids were stirred just before undergoing an ultrasonication process. The viscosity values were observed by the standard control rate rheometer (Contraves LS 40 ) at $25^{\circ} \mathrm{C}$. Their results indicated that the viscosity of nanofluids is much higher when the particle size is smaller. Eq. 3 proposed by Namburu et al. [52] does not consider the particle size effect. When comparing the values presented by these two studies, it is found that the relative viscosity of Kwek et al. [55] of $80 \mathrm{~nm}$ is 1.19 times higher than the value of Lu et al. [54] of $90 \mathrm{~nm}$ for the similar nanofluid samples and concentrations. This difference can be related to the surfactant and the producer. Timofeeva et al. [56] investigated the particle size effect on the viscosity of $\mathrm{SiC}$-water nanofluids with different particle sizes varying from 16 to $90 \mathrm{~nm}$. The viscosity of the nanofluids was measured by using a 
Brookfield DV-II+ viscometer at a temperature range of $15-45^{\circ} \mathrm{C}$. They stated that the nanofluids with smaller particles provide higher viscosity because of the smaller solid/liquid interfacial area of larger particles. Shanker et al. [57] developed a generalized regression equation to include the particle size effect.

$$
\mu_{n f}=\left(1.75+16.85 \varphi+23.5 \frac{\varphi^{2}}{d_{p}^{2}}\right) \exp \left(0.015+0.15 \varphi-31.3 \varphi^{2}+5.65 \frac{\varphi}{d_{p}}\right) T
$$

Eq. 6 is valid for the range of $30<T<80^{\circ} \mathrm{C}, 27<d_{p}<45 \mathrm{~nm}, \varphi<1 \%$. Furthermore, Shanker et al. [57] experimentally investigated the particle size effect on the viscosity of $\mathrm{Al}_{2} \mathrm{O}_{3}-$ Glycerol/water (70\% Glycerol, 30\% water) nanofluid at less than 1 vol.\% concentration. Their experimental data was not included in Fig. 2 due to the fact that the exact concentrations are not given by the authors. They prepared the samples by adding SDBS as the surfactant with $10 \%$ of the nanoparticle weight to the base fluid. Then, the mixture was stirred in a magnetic bath for 10 minutes. After the preparation of the mixture, the $\mathrm{Al}_{2} \mathrm{O}_{3}$ nanoparticles were added and stirred again continuously for 16 hours. To measure the viscosity of the nanofluids, a programmable R/S+ cylindrical rheometer with a temperature controlled bath was utilized. They concluded that the nanofluid with $27 \mathrm{~nm}$ particle size has shown higher viscosity than the one with $45 \mathrm{~nm}$. Esfe et al. [58] used Fe-EG nanofluids with three different particle sizes (40, 70 and $100 \mathrm{~nm}$ ) and vol. concentrations between $0.125-3 \%$. The Fe-EG suspension was stirred with an ultrasonic bath about 5 hours to break down the agglomeration and provide a uniform suspension. A Brookfield viscometer was utilized for the viscosity measurement of nanofluids in the temperature range of $26-55^{\circ} \mathrm{C}$. They concluded that the viscosity of nanofluids increases with the decrease of the particle size. A year later, Esfe et al. [59] carried out an experimental study on Fe-water nanofluids with three different diameters of nanoparticles $(37,71$ and $98 \mathrm{~nm})$. They prepared the samples 
by dispersing the nanoparticles in water using an ultrasonic vibrator for 120 minutes. An activator was used to cover the nanoparticles to stabilize the suspension; however, the type of the activator was not mentioned in the study. They measured the viscosity ratio for Fe-water under the ambient conditions with six different vol. concentrations varying from 0.0313 to $1 \%$. The measurement method of the viscosity was not mentioned. They concluded that the viscosity of the nanofluids depends on the size of the nanoparticles and increases with the decrease of the particle size. They used the experimental data to make curve fitting for the viscosity of the nanofluid and they proposed a simple equation to correlate viscosity as a function of $d_{p}$ and $\varphi$ :

$$
\frac{\mu_{n f}}{\mu_{b f}}=1+\left(0.1008 \varphi^{0.6974} d_{p}^{0.44708}\right)
$$

Agarwal et al. [60] examined the effect of the particle size on the viscosity of $\mathrm{Al}_{2} \mathrm{O}_{3}-$ kerosene nanofluid. The viscosity of the nanofluids was measured between $25-65^{\circ} \mathrm{C}$ by using a Brookfield LVDV-II digital viscometer with a cone type spindle. Oleic acid as a surfactant with 0.3 vol.\% concentration was added to the nanofluids to prevent particle agglomeration. Different ultrasonication time (30 min for 0.05 vol.\% to 3 hours for 1 vol.\%) was applied by a disruptor type ultrasonicator with $20 \mathrm{kHz}, 500 \mathrm{~W}$ power levels. They conducted the experiments with two different particle sizes of 13 and 50 $\mathrm{nm}$ and the vol. concentrations between $0.05-0.5 \%$. They observed that the increase in viscosity for smaller size is larger compared to that of the bigger particles due to the availability of the higher surface area. Rudyak et al. [61] measured the viscosity of $\mathrm{SiO}_{2}-\mathrm{EG}$ nanofluid with the particle sizes of $18.1,28.3$ and $45.6 \mathrm{~nm}$. The measurements were performed by a Brookfield LVDV-II+ Brookfield Viscometer at $25^{\circ} \mathrm{C}$. They concluded that the $\mathrm{SiO}_{2}-\mathrm{EG}$ nanofluid with smaller particles have higher viscosity than those with larger particles. Minakov et al. [62] experimentally 
investigated the viscosity of $\mathrm{SiO}_{2}$-water nanofluid with different particle sizes $(10,16$, 25 and $100 \mathrm{~nm}$ ). Experiments were carried out by Brookfield DV2T rheometer at $25^{\circ} \mathrm{C}$. They found that the viscosity of nanofluids increases with decreasing particle size.

Furthermore, results of several papers [63-67] indicated a irregular behavior in terms of particle size effect. Prasher et al. [63] conducted an experimental study on $\mathrm{Al}_{2} \mathrm{O}_{3}-$ propylene glycol nanofluid for three different nanoparticle diameters $(27,40$ and $50 \mathrm{~nm})$. At the production stage, colloidal mixture was subjected to ultrasonication. A controlled stress rheometer was used for the viscosity measurements between 30 and $60^{\circ} \mathrm{C}$. Their results depicted that the relative viscosity has an inconclusive trend and it is much higher than the value that can be predicted by Einstein's model. They concluded that it is probably caused by the agglomeration of nanoparticles. Anoop et al. [64] measured the $\mathrm{Al}_{2} \mathrm{O}_{3}-$ water nanofluid at $30^{\circ} \mathrm{C}$ by using an Ubbelohde viscometer, which works on the principle of evaluating the time required for a particular quantity of fluid to pass through a capillary bore. The $\mathrm{Al}_{2} \mathrm{O}_{3}$ nanoparticles were dispersed in water by using an ultrasonicator. Their results indicated that the nanofluid with 45 and $150 \mathrm{~nm}$ particle sizes has similar relative viscosity at 2 and $4 \mathrm{wt} . \%$ concentrations. But, the viscosity of the sample with $45 \mathrm{~nm}$ was higher than that with $150 \mathrm{~nm}$ particle size at $8 \mathrm{wt} . \%$ concentration. Since the study provided the weight concentrations, they have been converted to vol. concentrations by using Eq. 8 to make them comparable with the other studies:

$$
\varphi_{v o l}=\frac{\varphi_{w t} \rho_{b f}}{\rho_{n f}+\varphi_{w t}\left(\rho_{b f}-\rho_{n f}\right)}
$$

Meriläinen et al. [65] presented a detailed study on viscosity of $\mathrm{Al}_{2} \mathrm{O}_{3}, \mathrm{MgO}$ and $\mathrm{SiO}_{2}$ nanofluids using HAAKE falling ball viscometer in a temperature range of $10-50^{\circ} \mathrm{C}$. 
They reported that the ratio of nanofluid viscosity to the base fluid viscosity is found to be independent from temperature. Although they prepared the $\mathrm{Al}_{2} \mathrm{O}_{3}(8.2 \pm 3.1$ and 14$53 \mathrm{~nm})$ and $\mathrm{SiO}_{2}(6.5 \pm 1.8,65 \pm 34$ and $28-110 \mathrm{~nm})$ nanofluids up to 4 vol.\%, the highest concentration of $\mathrm{MgO}(21 \pm 10$ and $15-47 \mathrm{~nm})$ nanofluid was prepared as 2 vol.\% due to stability issues. They concluded that the average particle size does not have a significant effect on the viscosity of $\mathrm{MgO}$ and $\mathrm{SiO}_{2}$ nanofluids. However, the viscosity of $\mathrm{Al}_{2} \mathrm{O}_{3}$ nanofluid increases with smaller particle size.

Oliveria et al. [66] suggested that the most effective method for preventing agglomeration during the preparation of the nanofluid samples is the high-pressure homogenizer method, which consists of two microchannels that divide the main stream into two sub streams. The both streams divided were then recombined in a reacting chamber in which significant increase in the velocity of pressurized liquid streams resulted in the formation of cavitation in the liquid. The high energy of cavitation was used to break the clusters of nanoparticles. They performed their experimental study with $\mathrm{Ag}$-water nanofluid by altering the vol. concentration between $0.1-0.3 \%$ using two different particle sizes, namely 10 and $80 \mathrm{~nm}$. Viscosity measurements were carried out at $25^{\circ} \mathrm{C}$ by a cone plate viscometer. Their results indicated that the $\mathrm{Ag}$-water nanofluid has not revealed a systematic behavior response to the particle size. Although the relative viscosity of the nanofluid with $80 \mathrm{~nm}$ particle size is higher than the one with $10 \mathrm{~nm}$ size for 0.1 and 0.3 vol.\% concentrations, the sample with $10 \mathrm{~nm}$ particle size showed higher relative viscosity value than the sample with $80 \mathrm{~nm}$ for 0.2 vol.\% concentration. Yousaf et al. [67] worked on the viscosity of $\mathrm{Fe}_{3} \mathrm{O}_{4}-\mathrm{citric}$ acid nanofluid with two different particle sizes $(9 \pm 3$ and $20 \sim 30 \mathrm{~nm})$ with the concentrations of 1 to $10 \%$ in wt. The $\mathrm{Fe}_{3} \mathrm{O}_{4}-$ citric acid nanofluid with $20 \sim 30 \mathrm{~nm}$ was purchased, while the sample with $9 \mathrm{~nm}$ was synthesized in the laboratory by the co-precipitation method. 
Since the viscosity of the base fluid was not mentioned in this study, their experimental data was not included in Fig. 2 and Table 1. The viscosity of nanofluids was measured by a Brookfield viscometer with temperature ranges from 25 to $40^{\circ} \mathrm{C}$. Experimental viscosity value of the synthesized sample (smaller size) was higher than that of procured sample (larger size). However, the samples presented different viscosity trends. The viscosity of nanofluid with $20 \sim 30 \mathrm{~nm}$ particle size was found to increase with concentration, slowly and steadily. On the other hand, even the viscosity of nanofluid with $9 \mathrm{~nm}$ particle size indicated the same behavior with the larger sample size until 3.5 wt.\%. Beyond this point the viscosity values showed a significant increment. They explained that the nanoparticles with smaller sizes have larger surface areas and these nanosized particles have high energy surfaces since $50 \%$ of the atoms are at the surface and, therefore, surface properties and chemistry control the nanoparticles' behavior.

Fig. 3. Selected experimental data for the relationship between relative viscosity and vol. concentration.

Fig. 3 and Fig. 4 are provided to understand particle size effect better in the light of vol. concentration and temperature. Fig. 3 presents the variation of selected relative viscosity values in 0-100 $\mathrm{nm}$ particle size range. It is shown that almost all experiments indicated relative viscosity increments with increasing vol. concentration, except Oliveira et al. [66] which reported a contradiction. Variations of relative viscosity values of selected studies for temperature variation are portrayed in Fig. 4. According to Fig. 4 , temperature influences the relative viscosity, however any systematic behavior cannot be observed. 
Fig. 4. Selected experimental data for the relationship between relative viscosity and temperature.

Fig. 5. Selected experimental data for the relationship between relative viscosity $(\mu \mathrm{nn} / \mu \mathrm{bf})$ and particle size for nanofluids with 1 vol.\% concentration.

Comparative analysis of relative viscosity behavior with the particle size and other parameters are reduced and presented in Figs. 5 6. The relative viscosity of nanofluids with 1 vol.\% concentration was compared as a function of particle size in Fig. 5. For the similar particle concentration and material, the relative viscosity of Turgut et al. [50] of $30 \mathrm{~nm}$ is 1.15 and 1.19 times higher than that of Nguyen et al. [49] of $36 \mathrm{~nm}$ and Anoop et al. [64] of $45 \mathrm{~nm}$, respectively. Although, Turgut et al. [50] and Nguyen et al. [49] concluded that the relative viscosity of $\mathrm{Al}_{2} \mathrm{O}_{3}$ nanofluids increases with increase of particle size, findings of Esfe et al. [58,59] with Fe nanofluids contradicted as shown in Fig. 5. Additionally, Anoop et al. [64] and Chevalier et al. [53] obtained almost the same relative viscosity values for different particle sizes with $\mathrm{Al}_{2} \mathrm{O}_{3}-$ water and $\mathrm{SiO}_{2}-$ ethanol nanofluids, respectively. It is hard to deduce completely the effect of particle size on relative viscosity of nanofluids due to these contradictory results.

Fig. 6. Selected experimental data for the relationship between relative viscosity $(\mu \mathrm{nn} / \mu \mathrm{bf})$ and particle size for $\mathrm{Al}_{2} \mathrm{O}_{3}$-water nanofluids in the temperature range of 20 to $30^{\circ} \mathrm{C}$.

In Fig. 6, the relative viscosity of $\mathrm{Al}_{2} \mathrm{O}_{3}-$ water suspension which is the most preferred nanofluid are interpreted in the temperature range of $20-25^{\circ} \mathrm{C}$. It is seen that the samples with $0-50 \mathrm{~nm}$ particle size ranges were preferred than the samples with larger sizes. Moreover, it can be stated from the viscosity results of Jarahnejad et al. [36] that employing the samples with larger particle size may cause a non-systematic behavior. 
A proper particle size range could have been obtained for nanofluids by conducting more experimental study. Although stability and agglomeration are influenced by the particle size, the above mentioned studies are not complete enough for the interpretation. This makes it difficult to draw a clear conclusion for viscosity behavior that has a relationship with pressure drop.

\section{Viscosity models with particle size for nanofluids}

Many researches [28,53,69-72] considered the viscosity of nanofluids by comparing the experimental results with the classical models. They reported that classical models failed to show a good estimation of nanofluid viscosity due to not considering the particle size effect. However, several attempts were made on modeling the effective viscosity of nanofluids including the effect of particle size [73-78].

\subsection{Theoretical models}

Masoumi et al. [73] presented a viscosity model based on Brownian motion, considering the relative velocity between the nanoparticle and the base fluid of nanofluids. The developed model included five parameters (vol. concentration, particle size, temperature, nanoparticle density, and base fluid physical properties) as shown in Eq. 9. The distance between the centers of particles $(\delta)$ is evaluated from Eq. 10 which was developed by Sommerfeld [79]. The correction factor $(C)$ was calculated from Eq. 11 to account for simplified assumptions.

$$
\begin{aligned}
& \mu_{n f}=\mu_{b f}+\frac{\rho_{p} V_{B} d_{p}^{2}}{72 C \delta} \\
& \delta=\sqrt[3]{\frac{\pi}{6 \varphi} d_{p}} \\
& C=\mu_{b f}^{-1}(a \varphi+b)
\end{aligned}
$$


Hosseini et al. [74] developed another viscosity model based on the experimental data of Nguyen et al. [49] for water based $\mathrm{Al}_{2} \mathrm{O}_{3}$ nanofluid with the influence of vol. concentration, nanoparticle size, thickness of capping layer of the nanoparticles and temperature. They considered a least-squares regression to determine the model parameters, where $h$ is the hydrodynamic vol. concentration of $\mathrm{Al}_{2} \mathrm{O}_{3}$ nanoparticles, $r$ is the thickness of the capping layer, $d_{p}$ is the size of nanoparticle, $T$ is the temperature of nanofluid and $T_{o}$ is the reference temperature, $m$ is the constant that depends on the system properties and $\alpha, \omega, \gamma$ are empirical constants obtained from the experimental data.

$$
\frac{\mu_{n f}}{\mu_{b f}}=\exp \left[m+\alpha\left(\frac{T}{T_{0}}\right)+\omega\left(\varphi_{h}\right)+\gamma\left(\frac{d_{p}}{1+r}\right)\right]
$$

\subsection{Empirical models}

Azmi et al. [75] proposed a viscosity model by using different experimental data in the literature on water-based nanofluids of $\mathrm{Al}_{2} \mathrm{O}_{3}, \mathrm{CuO}, \mathrm{SiO}_{2}, \mathrm{ZnO}$, and $\mathrm{TiO}_{2}$ with particle sizes ranging from 20 to $170 \mathrm{~nm}$ and vol. concentration lower than $4 \%$. The model was dependent on the effects of vol. concentration, temperature and particle size on the effective viscosity of nanofluids, where $C_{1}$ is an empirical constant and the exponents $\alpha, \lambda$, and $\sigma$ are equal to $11.3,0.038$ and 0.061 , respectively.

$$
\frac{\eta_{n f}}{\eta_{b f}}=C_{1}\left(1+\frac{\varphi}{100}\right)^{\alpha}\left(1+\frac{T_{n f}}{100}\right)^{-\lambda}\left(1+\frac{d_{p}}{170}\right)^{-\sigma}
$$

Khanafer and Vafai [76] developed a general viscosity correlation for the effective viscosity of water based $\mathrm{Al}_{2} \mathrm{O}_{3}$ nanofluid from curve fitting of the experimental data $[49,64,80,81]$ existing in the literature. The model is valid for $\mathrm{Al}_{2} \mathrm{O}_{3}$ nanofluids with 
temperatures between 20 and $70^{\circ} \mathrm{C}$, nanoparticle diameters between 13 and $131 \mathrm{~nm}$ and vol. concentrations between 1 and $9 \%$.

$$
\begin{aligned}
& \mu_{n f}=-0.4491+\frac{28.837}{T}+0.574 \varphi-0.1634 \varphi^{2}+23.053 \frac{\varphi^{2}}{T^{2}}+0.0132 \varphi^{3}-2354.735 \frac{\varphi}{T^{3}} \\
& +23.498 \frac{\varphi^{2}}{d_{p}^{2}}-3.0185 \frac{\varphi^{3}}{d_{p}^{2}}
\end{aligned}
$$

Corcione [77] formulated a viscosity correlation shown in Eq. 15. He considered various experimental data of nanofluids consisting of $\mathrm{Al}_{2} \mathrm{O}_{3}, \mathrm{TiO}_{2}, \mathrm{SiO}_{2}$, and $\mathrm{Cu}$ nanoparticles where $d_{p}$ is the particle size, $M$ is the molecular weight of the base fluid, $\rho f$ is the mass density of base fluid at temperature $T_{o}=293 \mathrm{~K}, N$ is the Avogadro's number $\left(N=6.022 \times 10^{23} \mathrm{~mol}^{-1}\right)$ and $d f$ is the equivalent diameter of a base fluid molecule (Eq. 16). Their correlation is valid for a temperature range from 293 to 333 $\mathrm{K}$, vol. concentration range from 0.1 to $7.1 \%$ and a particle size ranging between 25 and $200 \mathrm{~nm}$.

$$
\begin{aligned}
& \frac{\mu_{n f}}{\mu_{b f}}=\frac{1}{1-34.87\left(\frac{d_{p}}{d_{f}}\right)^{-0.3} \varphi^{1.03}} \\
& d_{f}=0.1\left(\frac{6 M}{N \pi \rho_{f}}\right)^{1 / 3}
\end{aligned}
$$

Sekhar and Sharma [78] presented a regression equation including the effect of particle concentration, particle size and temperature of the base fluid. It is based on the experimental data [82-85] from the literature. The correlation is valid in the range of $13<d_{p}<100 \mathrm{~nm}$ particle size, $20<T_{n f}<50^{\circ} \mathrm{C}$ and $0.01<\varphi<4 \%$ vol. concentration. They 
observed that the model was in a good agreement with the experimental data of different authors with a deviation of -10 to $+18 \%$.

$$
\frac{\mu_{n f}}{\mu_{b f}}=0.935\left(1+\frac{T_{n f}}{70}\right)^{0.5602}\left(1+\frac{d_{p}}{80}\right)^{-0.05915}\left(1+\frac{\varphi}{100}\right)^{10.51}
$$

Different viscosity models including the particle size effect have been discussed above. It is seen that available models are valid for a limited range in terms of the critical variables. Therefore, it can be concluded that more comprehensive models need to be developed with wide operation ranges for the clear determination of nanofluids' viscosity behavior. The particle size and concentration, aggregation and the temperature must be considered simultaneously for the model development. More thorough experiments including a wide range of particle sizes need to be carried out in the future for reaching universal models.

\section{Concluding remarks}

Nanofluid related studies keep growing exponentially for the last two decades. However, commercialized application of the subject so far is not common, and many attempts are still being made by the scientific community. Utilized nanofluids in the existing literature show varying viscosity results due to the production method, nanoparticle and base fluid pairing, surfactant and measurement method. One of the prominent parameters which influences the viscosity of nanofluids is the particle size. Nonetheless, the number of studies on the effect of particle size is inadequate.

In this review, papers focused systematically on the size effect on nanofluid viscosity have been considered. It has been observed that there are discrepancies between discussed studies on viscosity values for different particle sizes even when their nanoparticle concentrations are similar. It is also evident that, according to 
collected data, the relative viscosity can increase up to $40 \%$ [56] or decrease up to $37 \%$ [49] by merely altering the particle size for the same nanofluid samples. Following are the conclusions drawn from this study that includes some possible reasons of these discrepancies:

- Some of the considered papers indicated an increment in viscosity values with decreasing particle size, while the others indicated an increment with increase of particle size.

- Production and measurement methods are different among the various studies available in the literatures. This variation restrains to draw a clear conclusion about the particle size effect on viscosity of nanofluids.

- Particle size range of the each study was limited. A remarkable number of discussed papers employed only two or three different particle size, which makes it difficult to have an interpretation about the effect of particle size.

- Among the evaluated studies, it is realized that information about the surfactant types is insufficient or missing. Additionally, evaluated studies are lacking in using surfactant at high temperatures. This is important, since, the physical phenomena between surfactant and nanoparticles may be influenced at high temperatures.

- Even in some cases, particle shape(s) is not introduced in literature. However, the effect of particle size again depends on the particle shape. If the particle size or diameters are the same but the shape is different as being spherical and cylindrical, then viscosity and other properties will differ.

- Since, stability and agglomeration are directly influenced by the particle size distribution of the nanofluid, they need to be considered prior to 
performing a viscosity study. Size distribution of nanoparticles in liquid should be provided rather than providing size distribution of nanoparticles in powder form.

For future works, wide and systematic range of parameters in terms of particle size, particle concentration and temperature should be employed for eliminating the discrepancies of the particle size effect. This effort will be helpful to develop new wellaccepted models. Moreover, presentations of production and measurement methods and type and quantity of surfactant are important for providing better comparisons. Lastly, studies related to the degradation of surfactants functional ability at high temperature and more rigorous stability analyses are needed.

\section{Acknowledgements}

This work has been supported by Research Foundation of Dokuz Eylul University (project no: 2013.KB.FEN.016).

\section{References}

[1] Masuda H, Ebata A, Teramae K. Alteration of thermal conductivity and viscosity of liquid by dispersing ultra-fine particles (Dispersion of $\mathrm{Al}_{2} \mathrm{O}_{3}, \mathrm{SiO}_{2}$ and $\mathrm{TiO}_{2}$ ultra-fine particles). Netsu Bussei 1993;4:227-33.

[2] Choi SUS. Enhancing thermal conductivity of fluids with nanoparticles. ASMEPubl-Fed 1995;231:99-106.

[3] Buschmann $\mathrm{MH}$. Nanofluids in thermosyphons and heat pipes: Overview of recent experiments and modelling approaches. Int J Therm Sci 2013;72:1-17.

[4] Kasaeian A, Eshghi AT, Sameti M. A review on the applications of nanofluids in solar energy systems. Renew Sustain Energy Rev 2015;43:584-98.

[5] Saidur R, Meng TC, Said Z, Hasanuzzaman M, Kamyar A. Evaluation of the effect of nanofluid-based absorbers on direct solar collector. International J Heat Mass Trans 2012;55(21):5899-907. 
[6] Turgut A, Elbasan E. Nanofluids for electronics cooling. In: Design and Technology in Electronic Packaging (SITME), 2014 IEEE 20th International Symposium for IEEE. 2014. p. 35-37

[7] Hsieh SS, Leu HY, Liu HH. Spray cooling characteristics of nanofluids for electronic power devices. Nanoscale Res Lett 2015;10(1):1-16.

[8] ljam A, Saidur R. Nanofluid as a coolant for electronic devices (cooling of electronic devices). Appl Therm Eng 2012;32:76-82.

[9] Leong KY, Saidur R, Kazi SN, Mamun AH. Performance investigation of an automotive car radiator operated with nanofluid-based coolants (nanofluid as a coolant in a radiator). Appl Therm Eng 2010;30(17):2685-92.

[10] Hussein AM, Bakar RA, Kadirgama K. Study of forced convection nanofluid heat transfer in the automotive cooling system. C Stud Therm Eng 2014;2:50-61.

[11] Barrett TR, Robinson S, Flinders K, Sergis A, Hardalupas Y. Investigating the use of nanofluids to improve high heat flux cooling systems. Fusion Eng Des 2013;88(9):2594-7.

[12] Mahbubul $\mathbb{M}$, Saidur R, Amalina MA. Thermal conductivity, viscosity and density of R141b refrigerant based nanofluid. Procedia Eng 2013;56:310-15.

[13] Saidur R, Kazi, SN, Hossain MS, Rahman MM, Mohammed HA. A review on the performance of nanoparticles suspended with refrigerants and lubricating oils in refrigeration systems. Renew Sustain Energy Rev 2011;15(1):310-23.

[14] Bi S, Guo K, Liu Z, Wu J. Performance of a domestic refrigerator using $\mathrm{TiO}_{2}-$ R600a nano-refrigerant as working fluid. Energy Convers and Manag 2011;52(1):733-7.

[15] Kumar V, Tiwari AK, Ghosh SK. Application of nanofluids in plate heat exchanger: A review. Energy Convers Manag 2015;105:1017-36.

[16] Said Z, Saidur R, Sabiha MA, Hepbasli A, Rahim NA. Energy and exergy efficiency of a flat plate solar collector using $\mathrm{pH}$ treated $\mathrm{Al}_{2} \mathrm{O}_{3}$ nanofluid. $\mathrm{J}$ Clean Prod 2016;112:3915-26.

[17] Lee S, Choi SS, Li SA, Eastman JA. Measuring thermal conductivity of fluids containing oxide nanoparticles. J Heat Trans 1999;121(2):280-9.,

[18] Eastman JA, Choi SUS, Li S, Yu W, Thompson LJ. Anomalously increased effective thermal conductivities of ethylene glycol-based nanofluids containing copper nanoparticles. Appl Phys Lett 2001;78(6);718-20. 
[19] Xie H, Wang J, Xi T, Liu Y, Ai F, Wu Q. Thermal conductivity enhancement of suspensions containing nanosized alumina particles. J Appl Phys 2002;91(7);4568-72.

[20] Ben-Mansour R, Habib MA. Use of nanofluids for improved natural cooling of discretely heated cavities. Adv Mech Eng 2013;5:383267.

[21] Li Q, Xuan $Y$ (2000). Experimental investigation on transport properties of nanofluids. In: Heat transfer science and technology 2000, Higher Education Press, Beijing. 2000. p. 757-762

[22] Pozhar LA. Structure and dynamics of nanofluids: Theory and simulations to calculate viscosity. Phys Rev E 2000;61(2);1432.

[23] Wang B., Zhou L., Peng X. Viscosity, thermal diffusivity and Prandtl number of nanoparticle suspensions. Prog Nat Sci, 2004:14(10):922-926.

[24] Azmi WH, Sharma KV, Mamat R, Najafi G, Mohamad MS. The enhancement of effective thermal conductivity and effective dynamic viscosity of nanofluids $-A$ review. Renew Sustain Energy Rev 2016;53:1046-58.

[25] Meyer JP, Adio SA, Sharifpur M, Nwosu PN. The viscosity of nanofluids: A review of the theoretical, empirical, and numerical models. Heat Trans Eng 2016;37(5):387-421.

[26] Mahbubul IM, Shahrul IM, Khaleduzzaman SS, Saidur R, Amalina MA, Turgut A. Experimental investigation on effect of ultrasonication duration on colloidal dispersion and thermophysical properties of alumina-water nanofluid. Int $\mathrm{J}$ Heat Mass Transf 2015;88:73-81.

[27] Turgut A, Tavman I, Chirtoc M, Schuchmann HP, Sauter C, Tavman S. Thermal conductivity and viscosity measurements of water-based $\mathrm{TiO}_{2}$ nanofluids. Intl $\mathrm{J}$ Thermophys 2009;30(4):1213-26.

[28] Sundar LS, Sharma KV, Naik MT, Singh MK. Empirical and theoretical correlations on viscosity of nanofluids: A review. Renew Sustain Energy Rev 2013;25:670-86.

[29] Bahiraei M, Hosseinalipour SM, Zabihi K, Taheran E (2012). Using Neural Network for Determination of Viscosity in Water- $\mathrm{TiO}_{2}$ Nanofluid. Adv Mech Eng 2012;4:742680.

[30] Wang L, Chen H, Witharana S. Rheology of Nanofluids: A Review. Recent Pat Nanotechnol 2013;7(3):232-46. 
[31] Gaganpreet, Srivastava S. Viscosity of nanofluids: particle shape and fractal aggregates. Phys Chem Liq 2014;53:174-86.

[32] Timofeeva EV, Routbort JL, Singh D. Particle shape effects on thermophysical properties of alumina nanofluids. J Appl Phys 2009;106:1-10.

[33] Jeong J, Li C, Kwon Y, Lee J, Kim SH, Yun R. Particle shape effect on the viscosity and thermal conductivity of ZnO nanofluids. Int J Refrig 2013;36:223341.

[34] Mingzheng Z, Guodong X, Jian L, Lei C, Lijun Z. Analysis of factors influencing thermal conductivity and viscosity in different kinds of surfactant solutions. Exp Therm Fluid Sci 2012;36:22-29.

[35] Li X, Zhu D, Wang X. Experimental investigation on viscosity of $\mathrm{Cu}-\mathrm{H}_{2} \mathrm{O}$ nanofluids. J Wuhan Univ Technol Mater Sci Ed 2009;24:48-52.

[36] Jarahnejad M, Haghighi EB, Saleemi M, Nikkam N, Khodabandeh R, Palm B et al. Experimental investigation on viscosity of water-based $\mathrm{Al}_{2} \mathrm{O}_{3}$ and $\mathrm{TiO}_{2}$ nanofluids. Rheol Acta 2015;54:411-22.

[37] Sergis A, Hardalupas Y. Anomalous heat transfer modes of nanofluids: a review based on statistical analysis. Nanoscale Res Lett 2011;6:391.

[38] Kumar PM, Kumar J, Suresh S. Review on nanofluid theoretical viscosity models. UEIR 2012;1(2):182-8.

[39] Mishra PC, Mukherjee S, Nayak SK, Panda A. A brief review on viscosity of nanofluids. International Nano Letters 2014;4(4)109-20.

[40] Elçioğlu EB, Yazıcıoğlu AG, Kakaç S. A comparative evaluation on nanofluid viscosity. J Therm Sci Technol 2014;34(1) 137-151.

[41] Nwosu PN, Meyer J, Sharifpur M. A review and parametric investigation into nanofluid viscosity models. J Nanotechnol Eng Med 2014;5(3):031008.

[42] Sharma AK, Tiwari AK, Dixit AR. Rheological behavior of nanofluids: A review. Renew Sustain Energy Rev 2016;53:779-91.

[43] Bashirnezhad K, Bazri S, Safaei MR, Goodarzi M, Dahari M, Mahian O et al. Viscosity of nanofluids: A review of recent experimental studies. Int Commun Heat Mass Trans 2016;73:114-23.

[44] Zhao N, Li S, Yang J. A review on nanofluids: Data-driven modeling of thermalphysical properties and the application in automotive radiator. Renew Sustain Energy Rev2016;66;596-616. 
[45] Akilu S, Sharma KV, Baheta AT, Mamat R. A review of thermophysical properties of water based composite nanofluids. Renew Sustain Energy Rev 2016;66;654-78.

[46] Ravisankar B, Tara Chand V. Influence of nanoparticle volume fraction, particle size and temperature on thermal conductivity and viscosity of nanofluids - $A$ review. International J Automot Mech Eng 2013;8:1316-38.

[47] Goharshadi EK, Ahmadzadeh H, Samiee S, Hadadian M. Nanofluids for heat transfer enhancement-A review. Phys Chem Res 2013;1(1):1-33.

[48] He Y, Jin Y, Chen H, Ding Y, Cang D, Lu H. Heat transfer and flow behaviour of aqueous suspensions of $\mathrm{TiO}_{2}$ nanoparticles (nanofluids) flowing upward through a vertical pipe. Int $\mathrm{J}$ Heat Mass Transf 2007;50:2272-81.

[49] Nguyen CT, Desgranges F, Roy G, Galanis N, Maré T, Boucher S, et al. Temperature and particle-size dependent viscosity data for water-based nanofluids - Hysteresis phenomenon. Int J Heat Fluid Flow 2007;28:1492-506.

[50] Turgut A, Saglanmak S, Doganay S. Experimental investigation on thermal conductvity and viscosity of nanofluids: particle size effect. J Fac Eng Archit Gazi U, 2016;31(1):95-103.

[51] Namburu PK, Kulkarni DP, Dandekar A, Das DK. Experimental investigation of viscosity and specific heat of silicon dioxide nanofluids. Micro Nano Lett, IET 2007;2(3):67-71.

[52] Namburu PK, Das DK, Tanguturi KM, Vajjha RS. Numerical study of turbulent flow and heat transfer characteristics of nanofluids considering variable properties. Int J Therm Sci 2009;48:290-302.

[53] Chevalier J, Tillement O, Ayela F. Rheological properties of nanofluids flowing through microchannels. Appl Phys Lett 2007;91:2007-9.

[54] Lu WQ, Fan QM. Study for the particle's scale effect on some thermophysical properties of nanofluids by a simplified molecular dynamics method. Eng Anal Bound Elem 2008;32:282-9.

[55] Kwek D, Crivoi A, Duan F. Effects of Temperature and Particle Size on the Thermal Property Measurements of $\mathrm{Al}_{2} \mathrm{O}_{3}$ - Water Nanofluids. J Chem Eng Data 2010;55(12):5690-5.

[56] Timofeeva EV, Smith DS, Yu W, France DM, Singh D, Routbort JL. Particle size and interfacial effects on thermo-physical and heat transfer characteristics of water-based $\alpha$-SiC nanofluids. Nanotechnol 2010;21(21);215703. 
[57] Shanker N, Reddy M, Rao V. On prediction of viscosity of nanofluids for low volume fractions of nanoparticles. Int J Eng Res Technol 2012;1(8):1-10.

[58] Esfe MH, Saedodin S, Mahian O, Wongwises S. Efficiency of ferromagnetic nanoparticles suspended in ethylene glycol for applications in energy devices: Effects of particle size, temperature, and concentration. Int Commun Heat Mass Transf 2014;58:138-46.

[59] Esfe MH, Saedodin S, Wongwises S, Toghraie D. An experimental study on the effect of diameter on thermal conductivity and dynamic viscosity of $\mathrm{Fe} /$ water nanofluids. J Therm Anal Calorim 2015;119:1817-24.

[60] Agarwal DK, Vaidyanathan A, Sunil Kumar S. Investigation on convective heat transfer behavior of kerosene-Al2O3 nanofluid. Appl Therm Eng 2015;84:64-73.

[61] Rudyak VY, Minakov AV, Krasnolutskii SL. Physics and mechanics of heat exchange processes in nanofluid flows. Phys Mesomech 2016;19(3);298-306.

[62] Minakov AV, Guzei DV, Pryazhnikov MI, Zhigarev VA, Rudyak VY. Study of turbulent heat transfer of the nanofluids in a cylindrical channel. Int $J$ Heat Mass Trans 2016;102; 745-55.

[63] Prasher R, Song D, Wang J, Phelan P. Measurements of nanofluid viscosity and its implications for thermal applications. Appl Phys Lett 2006;89:133108.

[64] Anoop KB, Sundararajan T, Das SK. Effect of particle size on the convective heat transfer in nanofluid in the developing region. Int $\mathrm{J}$ Heat Mass Transf 2009;52:2189-95.

[65] Meriläinen A, Seppälä A, Saari K, Seitsonen J, Ruokolainen J, Puisto S, et al. Influence of particle size and shape on turbulent heat transfer characteristics and pressure losses in water-based nanofluids. Int $\mathrm{J}$ Heat Mass Trans 2013;61;439-48.

[66] Oliveira GA, Bandarra Filho EP, Wen D. Synthesis and characterization of silver/water nanofluids. High Press 2014;43:69-83.

[67] Yousaf A B, Khan M, Imran M, Usman M, Jamal MA. Influence of Particle Size on Density, Ultrasonic Velocity and Viscosity of Magnetite Nanofluids at Different Temperatures. Nano 2014;09:1450089.

[68] Vatani A, Lloyd P, Dao DV. A survey of practical equations for prediction of effective thermal conductivity of spherical-particle nano fluids. J Mol Liq 2015;211:712-33. 
[69] Krieger IM, Dougherty TJ. A mechanism for non-Newtonian flow in suspensions of rigid spheres. Trans. Soc. Rheol, 1959;3(1):137-52.

[70] Murshed SMS, Leong KC, Yang C. Thermophysical and electrokinetic properties of nanofluids - A critical review. Appl Therm Eng 2008;28:2109-25

[71] Mahbubul IM, Saidur R, Amalina MA. Latest developments on the viscosity of nanofluids. Int J Heat Mass Transf 2012;55:874-85.

[72] Yiamsawas T, Mahian O, Dalkilic AS, Kaewnai S, Wongwises S. Experimental studies on the viscosity of $\mathrm{TiO}_{2}$ and $\mathrm{Al}_{2} \mathrm{O}_{3}$ nanoparticles suspended in a mixture of ethylene glycol and water for high temperature applications. Appl Energy 2013;111:40-5.

[73] Masoumi N, Sohrabi N, Behzadmehr A. A new model for calculating the effective viscosity of nanofluids. J Phys D Appl Phys, 2009;42:055501.

[74] Hosseini SM, Moghadassi AR, Henneke DE. A new dimensionless group model for determining the viscosity of nanofluids. J Therm Anal Calorim 2010;100:8737.

[75] Azmi WH, Sharma K V, Mamat R, Alias ABS, Misnon II. Correlations for thermal conductivity and viscosity of water based nanofluids. IOP Conf Ser Mater Sci Eng 2012;36:012029.

[76] Khanafer K, Vafai K. A critical synthesis of thermophysical characteristics of nanofluids. Int J Heat Mass Transf 2011;54:4410-28.

[77] Corcione M. Empirical correlating equations for predicting the effective thermal conductivity and dynamic viscosity of nanofluids. Energy Convers Manag 2011;52:789-93.

[78] Sekhar YR, Sharma KV. Study of viscosity and specific heat capacity characteristics of water-based $\mathrm{Al}_{2} \mathrm{O}_{3}$ nanofluids at low particle concentrations. $\mathrm{J}$ Exp Nanosci 2013;10:86-102.

[79] Sommerfeld M (2000). Theoretical and Experimental Modeling of Particulate Flow. Lect Ser 2000;6:3-7

[80] Putra N, Roetzel W Das, SK. Natural convection of nano-fluids. Heat Mass Trans 2003;39(8-9):775-84.

[81] Pak BC, Cho Yl. Hydrodynamic and heat transfer study of dispersed fluids with submicron metallic oxide particles. Exp Heat Trans Int J 1998;11(2):151-70. 
[82] Kulkarni DP, Vajha RS, Das DK, Oliva D. Application of aluminum oxide nanofluids in diesel electric generator as jacket water coolant. Appl Therm Eng 2008;28(14):1774-81.

[83] Murshed SS. Simultaneous measurement of thermal conductivity, thermal diffusivity, and specific heat of nanofluids. Heat Trans Eng 2012;33(8):722-31.

[84] Zhou S, Ni R. Measurement of the specific heat capacity of water-based $\mathrm{Al}_{2} \mathrm{O}_{3}$ nanofluid. Appl Physi Lett 2008;92(9):093123.

[85] O'Hanley H, Buongiorno J, McKrell T, Hu LW. Measurement and model validation of nanofluid specific heat capacity with differential scanning calorimetry. Adv Mech Eng 2012;4:181079. 